\title{
Non-stationary Job Search with Firing: A Structural Estimation
}

\author{
J. Ignacio Garcia-Perez \\ CEMFI and Universidad Complutense
}

Working Paper No. 9802

July 1998

I am indebted to my thesis advisor, Samuel Bentolila, and to Manuel Arellano and Pedro Mira for their helpful comments and guidance. I would also like to thank Arantza Gorostiaga and Namkee Ahn for their advice and the participants in seminars at CEMFI, Universidad del País Vasco, Universidad de Alcalá and at the Conference on Panel Data and Structural Labour Market Models (June, 1998) for all their comments. All remaining errors are mine. (E-mail address: garcia@cemfi.es).

CEMFI, Casado del Alisal 5, 28014 Madrid, Spain.

Tel: 341 4290551, fax: 341 4291056, www.cemfi.es. 


\begin{abstract}
This paper modifies Van den Berg's (1990) nonstationary model of search, considering the existence of a firing probability. The presence of firing makes unemployed workers lower their reservation wage because of the entitlement effect embodied in accepting a job offer. In this nonstationary environment, reservation wages have a stronger time-dependence than without firing.

The model is estimated structurally using Spanish data for the period 1985-1996. The main finding from this estimation is that, although the decrease in reservation wages is the main determinant of the change in the hazard rate for the first four months, later on, the only effect comes from the job offer arrival rate, given that acceptance probabilities are roughly equal to one. These results are obtained with grouped duration and re-employment wage data, and controlling for the presence of unobserved heterogeneity in the offer arrival rate.
\end{abstract}




\section{Introduction}

In the recent past a large amount of research has been carried out about the job search behavior of unemployed workers. The analysis of unemployment duration has become an important tool for understanding better the issues behind the unemployment rate as an aggregate figure.

The classic labor supply model cannot explain important features of the typical problem of an unemployed worker searching for a job. Job search models, describing the behavior of unemployed individuals in a dynamic and uncertain world, characterize better the situation of unemployed workers.

Job search models are an application of sequential statistical decision theory to the problem of an unemployed worker searching for a new job. This search process takes place in a decentralized labor market where information is imperfect. In this environment, the worker maximizes his expected wealth by using a stopping strategy based on accepting an offer when the offered wage is equal to or higher than a critical value called the reservation wage. There have been two basic empirical approaches to job search models: the reduced-form and the structural approach. The basic difference between them is that, unlike the former, the latter incorporates all the restrictions that are implied by the theory in the estimation of the model.

Within the structural approach to job search, a traditional assumption has been stationarity: parameters determining worker behavior were supposed to be constant over the spell of unemployment. But this assumption is often at variance with reality. Estimated reduced-form search models usually result in manifest negative duration-dependence of the re-employment probability, even when unobserved heterogeneity is controlled for (see among 
others Meyer (1990) for US data, Narendranathan and Stewart (1993) for UK data, or Bover, Arellano and Bentolila (1997) for Spanish data). The natural way of taking into account this empirical fact is allowing for some nonstationarity in one or more parameters in the model. Such time-dependence is supported by various observed facts such as the lower number of offers arriving to long-term unemployed workers or the changes in the personal situation or the environment faced by the unemployed worker.

One of the main consequences of nonstationarity is that the reservation wage of unemployed workers falls over time. Different explanations for this fact have been proposed: finite horizon of search (Wolpin, 1987), existence of liquidity constrains (Mortensen, 1986), etc. One of the most influential articles in the field of non-stationary job search is Van den Berg's (1990). In that paper, nonstationarity is considered in a very general way: it can affect any parameter of the model in a form allowing for very different departures from stationarity.

The main objective of this paper is to implement a structural estimation of a model quite similar to Van den Berg's (1990) using Spanish data for the period 1985-1996. The theoretical model is non-stationary in a similar way to Van den Berg's (1990) but it contains a new element: there is an exogenous firing rate in the economy. Under this circumstance the unemployed worker knows that once employed, he can be fired and become unemployed again in the future. It is shown that this fact, in a non-stationary environment, makes the reservation wage be more strongly time-dependent than otherwise.

The estimation of the structural model is carried out using grouped data on unemployment duration and data on accepted wages. Moreover, this 
structural estimation is reinforced by controlling for unobserved heterogeneity using a mixture technique inspired in Heckman and Singer (1984). The likelihood function for this kind of data is somewhat novel and interesting because they are very common in the case of unemployment spell data bases. The main results of the model estimation are as follows. First, the predicted hazard is increasing up to the fourth month and decreasing thereafter, and this duration-dependence is clearly maintained once unobserved heterogeneity is controlled for. The structural estimation indicates that during the first four months, decreasing reservation wages are the main determinant of the hazard rate, but later on, reservation wages are so low that acceptance probabilities are practically equal to one, and so the hazard is equal to the offer arrival rate, also estimated to be decreasing along the unemployment spell. The decrease in reservation wages is due to the nonstationarity of the parameters and to the effect of the firing rate. In fact, compared to a no-firing situation, the estimated decrease of reservation wages is much larger. Thus, the effect of the firing rate which is identified in the theoretical model is very important for this decrease. With respect to other explanatory variables, the skill of unemployed workers shows a strong effect on the offer arrival rate and on the mean of the distribution of offered wages, both parameters being clearly higher for skilled workers. As a net effect of this variable, it is found that the estimated hazard rate for unskilled workers is higher than for skilled ones for the first four months of the spell, although for the following months, the probability of exiting unemployment is higher for skilled workers. Existing reduced-form estimations of this hazard with Spanish data (Bover et al., 1997 or Garcia-Perez, 1997) also present this crossing between the hazards 
for skilled and unskilled unemployed workers, although it happens at the end of the spell. Here, with the structural estimation, the proper effect of each variable in each period of the spell can be estimated better, avoiding the problem of reduced-form estimations, which can only estimate the net effect of each variable on the hazard. Therefore, the influence of skill on the hazard rate can be better grasped in this structural estimation.

Another important variable in all job search empirical studies is whether the worker receives unemployment benefits. The results show that this variable has a strong effect not only on the income of the unemployed worker but also on the offer arrival rate, which is much lower for workers with unemployment benefits. With this structural estimation, we can learn more about the known stylized fact that unemployment benefits have a negative effect on the hazard rate. In this paper, I find that the main effect is on the arrival of offers, which might be interpreted as a lower search effort of unemployed workers who receive unemployment benefits.

The structure of the paper is as follows. Section 2 presents the nonstationary job search model with firing, jointly with a few simulation exercises which help us understand better the results of the model. Section 3 describes the structural estimation, the data used, and the main results, and Section 4 concludes.

\section{The model}

Consider a continuous time economy where agents either work receiving a constant wage, $w$, or are unemployed and searching for a job. The following 
conditions are assumed:

(A1) Wage offers at time $t$ are random drawings from a distribution function $F(w, t)$ where $w \in[0, \infty)$ and $t$ is the amount of time the agent has been unemployed. ${ }^{1}$

(A2) Job offers arrive at random intervals following a Poisson process with arrival rate $\alpha(t) \in[0, \infty)$ defined for each period $t$.

(A3) During the spell of unemployment, the agent has an income $b(t) \in$ $[0, \infty)$, net of search costs. This income can be interpreted as the value of time for the unemployed worker, and it includes, among other things, unemployment benefits and other non-labor income.

(A4) When an offer is accepted, the agent works at the offered wage, $w$, but there is a firing rate $\delta(s) \in[0, \infty)$ which depends on job tenure, $s$.

(A5) $F(w, t), \alpha(t)$ and $b(t)$ are continuous functions of $t$ and $\delta(s)$ of $s .^{2}$

(A6) The individual has a constant subjective discount factor $\rho \in[0, \infty)$.

(A7) There exists some period $T$ such that all the parameters depending on unemployment duration are constant on $[T, \infty)$.

These assumptions, as in Van den Berg (1990), will ensure that the appropriate present values are well defined and will therefore guarantee the existence of an optimal strategy.

\footnotetext{
${ }^{1}$ Calendar time is assumed to start at the moment the individual becomes unemployed. Thus, $t$ refers both to calendar time and to the length of time over which the individual remains unemployed.

${ }^{2}$ These parameters can also be step functions of duration, as in Van den Berg (1990).
} 
Following the principles of dynamic programming, in a continuous time environment, the expected present value of future net income for an unemployed worker who is searching is defined as:

$$
U(t)=\int_{t}^{\infty}\left[\int_{t}^{\tau} b(u) e^{-\rho(u-t)} d u+e^{-\rho(\tau-t)} E_{w, \tau} \max (W(w), U(\tau))\right] d G(\tau, t)
$$

where $\tau$ is the time at which a new offer arrives. It has a distribution function $G(\tau, t)=1-\exp \left[-\int_{t}^{\tau} \alpha(x) d x\right]$, since $\alpha(t)$ is a hazard rate.

Thus, $U(t)$ is the discounted value of the unemployment income, $b(t)$, until $\tau$, plus the expected value of the optimal stopping decision at $\tau$. This expected value is the maximum between the expected present value of accepting the offer and receiving $w, W(w)$, and continuing to search one more period, $U(\tau)$.

The expected present value of stopping search and beginning to work at a wage $w$ is:

$$
W(w)=\int_{t}^{\infty}\left[\int_{t}^{v} w e^{-\rho(u-t)} d u+e^{-\rho(v-t)} U(0)\right] d H(v, t)
$$

That is, $W(w)$ is the discounted value of the wage received until $v$ plus the expected present value of being unemployed again when the worker is fired, $U(0)$. The distribution function of the firing time is the following: $H(v, t)=$ $1-\exp \left[-\int_{t}^{v} \delta(s-t) d s\right]=1-\exp \left[-\int_{0}^{v-t} \delta(y) d y\right]$.

If there were no duration dependence in the firing rate, the distribution function of firing time would be $H(v, t)=1-\exp [-\delta(v-t)]$ and the following closed form for $W(w)$ would be obtained: 


$$
W(w)=\frac{w}{\rho}+\left(U(0)-\frac{w}{\rho}\right) \frac{\delta}{\delta+\rho}
$$

By analogy with the case of a non-stationary firing rate, an expression for $W(w)$ similar to (3) can be obtained using the following re-definition: $\frac{\delta^{*}}{\delta^{*}+\rho}=\int_{t}^{\infty} e^{-\rho(v-t)} d H(v, t)$. In this expression, $\delta^{*}$ may be called the mean firing rate and it represents the evolution of the firing rate from the beginning of the employment spell to infinity. Thus, in the non-stationary general case we have:

$$
W(w)=\frac{w}{\rho}+\left(U(0)-\frac{w}{\rho}\right) \frac{\delta^{*}}{\delta^{*}+\rho}
$$

Thus, (3') shows that $W(w)$ is the wage, infinitely discounted at a rate $\rho$, plus the loss derived from being fired, discounted at a modified discount rate which includes the mean firing rate.

In this context, like in all job search models, every time an offer arrives the decision has to be made whether to accept it or to reject it and search further. The individual will be indifferent between working and searching one more period for a wage called reservation wage, $w_{R}(t)$. Thus, equating (1) and (3') we have that this wage verifies:

$$
U(t)=\frac{w_{R}(t)}{\rho}+\left(U(0)-\frac{w_{R}(t)}{\rho}\right) \frac{\delta^{*}}{\delta^{*}+\rho}
$$

Van den Berg (1990) uses a differential equation in $U(t)$ which facilitates deriving $w_{R}(t)$ :

$$
U^{\prime}(t)=\rho U(t)-b(t)-\alpha(t) \operatorname{Emax}(W(w, t)-U(t), 0)
$$


Using (4) and taking into account that $U(0)=\frac{w_{R}(0)}{\rho}$, i.e., the value of $U(t)$ when $t=0$, we have the following integro-differential equation for the reservation wage ${ }^{3}$ :

$$
w_{R}(t)=b(t)+\frac{\delta^{*}}{\delta^{*}+\rho}\left(w_{R}(t)-w_{R}(0)\right)+\frac{\alpha(t)}{\delta^{*}+\rho} \int_{w_{R}(t)}^{\infty}\left(w-w_{R}(t)\right) d F(w, t)+\frac{w_{R}^{\prime}(t)}{\delta^{*}+\rho}
$$

It is straightforward to show that $w_{R}(0)$ satisfies:

$$
w_{R}(0)=b(0)+\frac{\alpha(0)}{\delta^{*}+\rho} \int_{w_{R}(0)}^{\infty}\left(w-w_{R}(0)\right) d F(w, 0)+\frac{w_{R}^{\prime}(0)}{\delta^{*}+\rho}
$$

From (6) we can distinguish four terms in the reservation wage: $(i)$ the value of time for the unemployed worker, $b(t) ;(i i)$ the value associated with a future firing, which represents a loss if the reservation wage decreases with unemployment duration; ( $i i i)$ the expected discounted benefit associated with the arrival of a new offer, that is, the probability of an offer arriving times the marginal return to continued search given an offer at least equal to $w_{R}(t)$; and, $(i v)$ the appreciation or depreciation of the option represented by the reservation wage.

\subsection{Nonstationarity of the reservation wage}

The nonstationarity of the reservation wage is derived from the nonstationarity of the parameters of the model, which is established by the following assumptions: ${ }^{4}$

\footnotetext{
${ }^{3}$ If we take the firing rate to be equal to zero, this equation is the same as in Van den Berg (1990) or Mortensen (1986).

${ }^{4}$ The derivation of the nonstationarity of the reservation wage is similar to Van den Berg (1990).
} 
(K1) $b(t)>b(t+\tau), \forall t \in[0, T), \forall \tau>0$.

(K2) $\alpha(t)>\alpha(t+\tau), \forall t \in[0, T), \forall \tau>0$.

(K3) $F(w, t)$ first order stochastically dominates $F(w, t+\tau), \forall t \in[0, T), \forall \tau>$ 0 , which implies that $1-F(w, t)>1-F(w, t+\tau), \forall w \in[0, \infty)$.

(K4) $F(w, t)$ is a mean preserving spread of $F(w, t+\tau), \forall t \in[0, T), \forall \tau>0$, that is, $E(w, t)=E(w, t+\tau)$, and $\forall x \in[0, \infty)$,

$$
\int_{0}^{x} F(w, t) d w>\int_{0}^{x} F(w, t+\tau) d w
$$

The economic meaning of these assumptions is simple. The value of time for an unemployed worker decreases with the time the worker is unemployed because his income and unemployment benefits decline over time. The offer arrival rate and the wage offered are both smaller as time proceeds, as a result of the stigma effect that long-term unemployed workers may suffer (see Viswanath, 1989 or Berkovitch, 1990). The distribution of offers is more concentrated around its mean for the long-term unemployed, because the range of offers they can have access to is smaller and because they know more about this distribution (see Burdett and Viswanath, 1988). An important assumption is that people know how the parameters are related to the duration of unemployment.

In order to prove the time dependence exhibited by the reservation wage, it is helpful to define a stationary reservation wage, $w_{R}^{0}(t)$. This wage is the optimal reservation wage at time $t$, for all $t \geq 0$, if the environment should remain stationary after $t$, that is: 


$$
w_{R}^{0}(t)=b(t)+\frac{\delta^{*}}{\delta^{*}+\rho}\left(w_{R}^{0}(t)-w_{R}^{0}(0)\right)+\frac{\alpha(t)}{\delta^{*}+\rho} \int_{w_{R}^{0}(t)}^{\infty}\left(w-w_{R}^{0}(t)\right) d F(w, t)
$$

Using this concept, we can prove that $w_{R}(t)$ is decreasing in $t$, in the following theorem:

Theorem 1 Let assumptions (A1) to (A7) be satisfied. Let one or more parameters satisfy assumptions (K1)-(K4) with strict inequality, while the remaining ones are constant over the time interval $[0, \infty)$. Then:

(i) $w_{R}(t)<w_{R}^{0}(t)$,

(ii) $w_{R}^{\prime}(t)<0$.

Proof : See Appendix A.

The meaning of the result that $w_{R}^{\prime}(t)<0$ is simple: any future decrease in the parameters of the model makes the value of search in the present be smaller than it would be if the parameters were constant, so the unemployed worker, anticipating these future changes, sets a smaller reservation wage as his spell of unemployment becomes longer.

Some simulation results which illustrate the effects of each parameter on reservation wages can be seen in Table 1 . In particular given a baseline parameter set, the table shows the effect of a $10 \%$ increase in each parameter $^{5}$ on reservation wages in three different periods of the spell (1 month, 12 months and 24 months). The main result emerging from this table is that, in the presence of the firing rate, the effect of each parameter on the reservation wage is

\footnotetext{
${ }^{5}$ Note that if a parameter is negative, a $10 \%$ increase will make it become smaller in absolute value.
} 
not always monotonic: an initial positive effect can change to negative after a few periods of unemployment. This result is present, for example, in the case of a higher level of unemployment benefits, represented by a larger $b_{0}$. In the first 12 months, reservation wages are larger because the individual receives a higher income (disincentive effect). But as the spell becomes sufficiently long, the unemployed worker realizes that the sooner he becomes employed, the sooner he will enjoy higher benefits if he is laid off again (entitlement effect) and, as a result, he is going to reduce the reservation wage although the benefits are, in fact, larger.

With respect to the levels of the parameters at $t=0$, the largest effects are those of the mean of the distribution of wages and of the offer arrival rate. Both effects grow with the duration of unemployment. Better chances of future offers lead to higher reservation wages. Note also that the firing rate has a strong negative effect on reservation wages. With respect to the slopes of the parameters, their reduction causes an increase in reservation wages for all the parameters except for the variance of wages. The same explanation as before can be applied here.

\subsection{The effect of the firing rate}

What is new in this model is the presence of a firing rate. Let us consider its effects on the reservation wage in a more detailed way.

Intuition suggests that a worker ought to demand a higher wage if he is going to accept a job with a higher firing rate. As far as he is going to bear more uncertainty, he should demand a higher compensation. However, in the present model, like in other search models with firing (see for example Devine 
and Kiefer, 1991), the relation between the reservation wage and the firing rate is negative. With respect to the no-firing situation, i.e. Van den Berg (1990), the reservation wage is smaller now through two different channels. The first one is the known discounting effect present in the third and the fourth terms of $w_{R}(t)$ : when there is a future possibility of firing, the worker discounts the future at a higher rate. The second effect derives from the nonstationarity of the model and can be named the entitlement effect. This second effect takes into account that $w_{R}(t)$ is decreasing in $t$, as was proved before. Thus, if the unemployed worker is fired he will have a maximum reservation wage, $w_{R}(0)$, and so, he will be better off than in the present situation. In addition, the slope of the reservation wage is smaller, which can be easily seen by taking derivatives of $w_{R}^{\prime}(t)$ with respect to $\delta^{*}$. Thus, if the reservation wage is decreasing with $t$, the presence of a positive firing rate will make it decrease faster. The firing rate can even make reservation wages be equal to zero from a certain duration of the unemployment spell.

The entitlement effect can be better understood if we take into consideration the nonstationarity of the parameters. The unemployed worker knows that these parameters decrease with the time over which he remains unemployed. Hence, he knows that in the following period of the present unemployment spell, his income or his chances of a new offer will be lower. But he also knows that if he is hired, then in the case of a future firing he will have access to greater values of all the parameters of the model. Thus, taking these elements into account, the worker gives a positive value to a future firing. He does not care very much about the future firing because he knows he will be better off than he currently is, given that his situation as unemployed 
is becoming worse.

Labeling this as the entitlement effect refers to the fact that a job makes workers regain eligibility to unemployment benefits in case of future unemployment, provided that the job lasts long enough. But this effect is also present with respect to other parameters of the model. Once in work, the worker acquires attributes which are more valued by firms and this fact makes the offer arrival rate and the offered wages, for instance, be higher at the beginning of a possible new spell of unemployment in the future. For this reason, the worker fixes a lower reservation wage.

Of course, this effect comes from assuming that the situation at the beginning of the unemployment spell is the same whatever the duration of the previous job was. This is clearly at odds with the observed fact that, for example, unemployment benefits depend on the length of the previous job and on its associated wage. However, given the difficulty of controlling for these aspects, I omit them in the analysis.

This effect of the firing rate, in particular regarding its relation with unemployment benefits, is already mentioned in Atkinson and Micklewright (1991) or in Usategui (1993). In relation to the offer arrival rate, the effect of the firing rate can be seen in models such as those in Wright (1987) or Hey and Mavromaras (1981).

It must be noted that different firing rates will cause different mean firing rates and so, different patterns of reservation wages. In fact, workers facing higher firing rates will have lower reservation wages. In addition, workers with firing rates which decrease more quickly with job tenure will have higher reservation wages, because their mean firing rates will be smaller. All these 
effects can be seen in Table 2. This table shows the effects of different values of the firing rate on reservation wages and on their evolution during the spell of unemployment. In particular, we can see that a positive firing rate, say a constant firing rate of $4 \%$ per month, makes the reservation wage in the first month be $38 \%$ lower than with no firing (101 with firing and 163 without firing), and that in the first 18 months, the decrease in reservation wages is more than three times larger. Moreover, it is observed that reservation wages become equal to zero after a certain month once the firing rate is high enough. Finally, a faster decrease of the firing rate makes the mean firing rate be much lower and, therefore, the reduction in reservation wages is not so important.

\subsection{The hazard rate}

Given the expression of the reservation wage, equation (6), the probability of exiting unemployment in $t$, conditional on not having exited before, the hazard rate, $\phi(t)$, is defined as:

$$
\phi(t)=\alpha(t)\left[1-F\left(w_{R}(t), t\right)\right]
$$

that is, the probability that an offer arrives times the probability that this offer is acceptable. The time dependence of the hazard can be seen from the derivative of $\phi(t)$ with respect to $t$ :

$$
\phi^{\prime}(t)=\alpha^{\prime}(t)\left[1-F\left(w_{R}(t), t\right)\right]-\alpha(t)\left[f\left(w_{R}(t), t\right) w_{R}^{\prime}(t)+\frac{\partial F\left(w_{R}(t), t\right)}{\partial t}\right]
$$

In this equation we can see that the hazard rate depends on the duration 
of the unemployment spell through three sources: the offer arrival rate, the reservation wage and the wage offer distribution function.

Given (K1) to $(\mathrm{K} 4)$ we have that $\alpha^{\prime}(t)<0$ and $w_{R}^{\prime}(t)<0$, but we can say nothing about the time dependence of the wage distribution function. So we are not able to find the shape of the time dependence of the hazard rate.

However, in reduced-form estimates of $\phi(t)$ for Spanish data, for example in Bover et al. (1997) or Garcia-Perez (1997), we can see that there is a period $t^{*}$ when $\phi^{\prime}(t)=0$, such that before $t^{*}$ the hazard rate is increasing and after $t^{*}$ it is decreasing. This fact would imply that before $t^{*}$ the decrease in the reservation wage is the main effect on $\phi(t)$ but after $t^{*}$ the falling offer arrival rate more than offsets the declining reservation wage. This explanation implicitly assumes that, as has been obtained in the simulations exercises just presented, the effect of the wage offer distribution is of secondary importance.

As an empirical illustration, the effects of each parameter on hazard rates can be seen in the last three columns of Table 1 . The results here are not so clear-cut as those on reservation wages. The reason is that some parameters may affect the hazard through different routes. An increase in the offer arrival rate increases the hazard, so its direct effect dominates. However, the mean of the distribution of offered wages has a positive effect in the first 12 months, but later on the indirect effect via reservation wages dominates and so the hazard decreases after that time.

\section{Structural estimation}

The estimation of the model is performed with Spanish data: the Spanish Continuous Family Expenditure Survey (Encuesta Continua de Presupuestos 
Familiares (ECPF)) for the period 1985-1996. The ECPF is a rotating panel based on a survey conducted by the Instituto Nacional de Estadistica (INE, Spanish National Statistical Office). It reports interviews for about 3,200 households every quarter. One eighth of the sample is renewed quarterly and hence an individual can be followed for a maximum of two consecutive years. This source gives information on unemployed workers over their spells of unemployment and on their post-unemployment wages, in addition to information on consumption and other household characteristics.

The structure of this section is the following. First, there is a basic description of the data set. Secondly, the way the structural model is estimated and some issues of identification are explained, and lastly the results are presented and discussed.

\subsection{The data set}

The estimation sample is composed of unemployed household heads, who are the only group for which the educational level is reported. Also, I restrict the sample to married men to reduce heterogeneity, since I am not able to introduce many regressors in the estimation (see below).

The individuals in the sample are all entrants to unemployment. The observed spells can be either complete, if the worker finds a job during the survey interval or censored, if he remains unemployed at the time of leaving the sample. For the completed spells, the re-employment wage is computed for those who continue answering the survey two quarters after the unemployment spell ends, from the labor income of the second quarter of employment (see Appendix B). The reason for doing this is that, due to the structure 
of the survey, the worker has to report his labor market status in the last week before the interview. Hence, a worker who answers he is employed a certain quarter, after a spell of unemployment, cannot be classified with total certainty as employed for the whole period. Thus, if in the second quarter subsequent he answers that he is employed, there are fewer doubts about the amount being a quarterly income.

As we can see in Table 3, there are 802 completed spells of unemployment and 661 censored spells. Of the former, 424 have an observed re-employment wage. The shape of the Kaplan-Meier estimates of the hazard rate and the histogram of re-employment wages, which are expressed in real terms of December 1996, can be seen in Figures 1 and 2, respectively.

Although the ECPF is a quarterly survey, it is possible to calculate monthly values of the variables. Monthly data are preferred because they will reflect better the non-stationarity of the job search behavior. Indeed, with monthly data the changing pattern of the reservation wage and of the hazard rate are likely to be estimated better. In order to obtain monthly data, a few transformation rules, explained in Appendix B, have been applied.

\subsection{The likelihood function}

One of the main objectives of this paper is to carry out a structural estimation of the search model developed in Section 2. Structural estimation attempts to recover the fundamental parameters identified by the theory. This is the objective of this section, as well as distinguishing the influence of some explanatory variables on these parameters. 
There are not many papers estimating dynamic programming models of individual behavior structurally. In the search context some references are Lancaster and Chesher (1983), Miller (1984) or Narendranathan and Nickell (1985). But one of the most influential articles in this area, which is the basis for the maximum likelihood estimation in this paper, is Wolpin (1987). That paper develops a discrete-time model of search which is non-stationary because of a finite horizon of search. It is estimated by maximum likelihood using data on duration, accepted wages and a few individual characteristics.

The estimation of my model is clearly inspired in Wolpin's technique but I adapt it to the data available: the model is in continuous time but the data are observed at discrete intervals of time, namely in months. For this reason, I write the likelihood function for grouped data, which are continuous but are observed in a discrete form.

The grouped or discrete hazard is used in other papers, like Meyer (1990) or Narendranathan and Stewart (1993). But these papers implement reducedform estimations. In this paper a likelihood function is developed which incorporates all the structure of the theoretical model for data on re-employment wages and grouped duration data. Since this is a very common case in data on unemployment spells, this likelihood could be useful for advancing in structural estimation of search models.

As stated before, given equation (9) for the continuous-time hazard of the model, the expression for the grouped or discrete hazard is as follows:

$$
h(t)=\operatorname{Pr}(T<t+1 \mid T \geq t)=1-\exp \left[-\int_{t}^{t+1} \phi(u) d u\right]=1-\exp [-\phi(t)]
$$


This is the hazard for the interval $[t, t+1)$. It is assumed that the parameters of the model are constant in this interval, so the last term of (11) can be obtained as the closed form of $h(t)$.

There are three types of individuals: those with completed spells and an observed re-employment wage, those with completed spells but without an observed re-employment wage and finally, those with censored spells. Thus, the likelihood function will have three different components: ${ }^{6}$

$$
L=\prod_{i=1}^{N}\left[\left(\operatorname{Pr}\left(t \leq T_{i}<t+1, W_{o_{i}}\right)\right)^{v_{i}}\left(\operatorname{Pr}\left(t \leq T_{i}<t+1\right)\right)^{1-v_{i}}\right]^{c_{i}}\left[\operatorname{Pr}\left(T_{i}>t\right)\right]^{1-c_{i}}
$$

For those with censored spells or completed spells but without an observed re-employment wage, the likelihood contribution is only a function of the grouped hazard $h_{i}(t)$ for the $t$ periods of unemployment:

$$
\begin{gathered}
\operatorname{Pr}\left(t \leq T_{i}<t+1\right)=h_{i}(t) \prod_{j=0}^{t-1}\left(1-h_{i}(j)\right) \\
\operatorname{Pr}\left(T_{i}>t\right)=\prod_{j=0}^{t}\left(1-h_{i}(j)\right)
\end{gathered}
$$

For those with completed spells and an observed re-employment wage the likelihood contribution is the following:

$$
\operatorname{Pr}\left(t \leq T_{i}<t+1, W_{o_{i}}\right)=\operatorname{Pr}\left(t \leq T_{i}<t+1, W_{o_{i}} \mid T_{i} \geq t\right) \prod_{j=0}^{t-1}\left(1-h_{i}(j)\right)
$$

\footnotetext{
${ }^{6} v_{i}$ is an indicator variable which has a value of 1 if the re-employment wage of the worker $i$ is observed and zero otherwise. $c_{i}$ is an indicator of censoring: it has a value of 1 if the individual $i$ has a completed spell and zero otherwise. $T_{i}$ represents worker $i$ 's unemployment spell duration and $W_{o_{i}}$ is his observed re-employment wage.
} 
where, in period $t$, this contribution is the joint probability of $T_{i}$ being in the interval $[t, t+1)$ and of observing the wage $W_{o_{i}}$.

Here, an assumption about the wage offer distribution is needed. As in the simulation exercises and like in other papers (Van den Berg, 1990 or Wolpin, 1987) it is assumed that wages have a lognormal distribution. In addition to this, as in Wolpin (1987) and justified by the construction of the wage data, the re-employment wages are assumed to be measured with error. Thus, the observed re-employment wage has the following expression:

$$
\ln W_{o_{i}}=\ln \bar{W}_{i}+u_{i}+\varepsilon_{i}
$$

where $u_{i}$ is normal with zero mean and variance $\sigma_{u}^{2}$, and $\varepsilon_{i}$, the measurement error, follows a normal distribution with zero mean and variance $\sigma_{\varepsilon}^{2}$. I assume that $\varepsilon_{i}$ is distributed independently of $u_{i}$.

The joint distribution of $W_{o}$ and $T \mid T \geq t$ is given by the following equations:

$$
\begin{aligned}
\operatorname{Pr}(t & \left.\leq T<t+1, W_{o} \mid T \geq t\right)=\int_{t}^{t+1} f_{W_{o}}\left(W_{o} \mid s\right) f_{T}(s \mid T \geq t) d s \\
& =f_{W_{o}}\left(W_{o} \mid t\right) \int_{t}^{t+1} f_{T}(s \mid T \geq t) d s=f_{W_{o}}\left(W_{o} \mid t\right) \times h(t)
\end{aligned}
$$

where, again, the assumption that the parameters of the model are constant between $t$ and $t+1$ is used. Note that the distribution of $W_{o}$ conditional on $t$ is the truncated distribution of the observed wages, with the reservation wage at $t$ being the truncation point, thus, $f_{W_{o}}\left(W_{o} \mid t\right)=f_{W_{o}}\left(W_{o} \mid W \geq W_{R}(t)\right)$.

Now, we only need an expression for $f_{W_{o}}\left(W_{o} \mid W \geq W_{R}(t)\right)$, where it has to be taken into account that, although the wages are measured with error, 
the worker compares the reservation wage with the true offered wage. Thus, we have:

$$
\begin{aligned}
f_{W_{o}}\left(W_{o} \mid W \geq W_{R}(t)\right) & =f(u+\varepsilon \mid u>\gamma)=\frac{\operatorname{Pr}(u+\varepsilon, u>\gamma)}{\operatorname{Pr}(u>\gamma)} \\
& =\frac{\operatorname{Pr}(u>\gamma \mid u+\varepsilon) f(u+\varepsilon)}{\operatorname{Pr}(u>\gamma)}
\end{aligned}
$$

where $\gamma=\ln W_{R}(t)-\ln \bar{W}$.

Finally, we can express the likelihood function in logarithms and in the usual way of expressing likelihood functions for grouped data (see Jenkins, 1995):

$$
\begin{aligned}
\ln £= & \sum_{i=1}^{N} \sum_{t=1}^{d_{i}}\left\{c_{i} y_{i t}\left[v_{i} \ln \left(f_{W_{o}}\left(W_{o} \mid t\right) h_{i}(t)\right)+\left(1-v_{i}\right) \ln \left(h_{i}(t)\right)\right]\right. \\
& \left.+\left(1-c_{i} y_{i t}\right) \ln \left(1-h_{i}(t)\right)\right\}
\end{aligned}
$$

Here the only new element is the dummy variable $y_{i t}$, which is equal to one if the individual $i$ has his last observation, $d_{i}$, at period $t$.

Given this likelihood function and taking into account the differential equation of the reservation wage, equation (6), we can estimate the parameters of the model, $\alpha(t), b(t), \delta^{*}, \bar{W}(t), \sigma_{u}$ and $\sigma_{\varepsilon}$ provided they are all identified.

The general idea behind identification is the following: given data on accepted wages, along with data on unemployment duration, the parameters of the wage offer distribution, $\bar{W}(t), \sigma_{u}$ and $\sigma_{\varepsilon}$ are clearly identified in the first component of the likelihood function. Further, given the result of the model by which any offer is accepted after a number of periods of unemployment 
because of the effect of the firing rate, I can identify the offer arrival rate in both the second or the third components of the likelihood function. Finally, the mean firing rate, $\delta^{*}$, and the value of time for unemployed workers, $b(t)$, are identified making use of the system of reservation wages from 0 to $T$. In the equation for $w_{R}(0), \delta^{*}$ and $b(0)$ are identified, and in the other equations the time-dependence of $b(t)$ can be identified.

\subsubsection{The likelihood function with unobserved heterogeneity}

Estimation involves solving for the reservation wages of each worker at each evaluation of the likelihood function. However, it is computationally very time consuming to solve for each worker. The solution I have adopted is to restrict the heterogeneity of the sample and to build types of workers based on a few dichotomous variables.

These requirements of the estimation procedure result in a lot of sample heterogeneity which is not captured by the explanatory variables used. This problem together with that of unobserved heterogeneity generating spurious negative duration dependence in the estimation, motivates the introduction and estimation of unobserved heterogeneity in the hazard rate.

The way of introducing such unobserved heterogeneity in the hazard rate can be either parametric or non-parametric. I have selected the second one and, inspired in the technique of Heckman and Singer (1984), I have defined a variable $\eta$ which is a discrete random variable with finite support, thus giving rise to a mixture model.

Although unobserved heterogeneity might be introduced in whatever parameter, I have introduced it only in the offer arrival rate. There is no reason 
to choose this parameter, but the estimation of unobserved heterogeneity in more than one parameter would be very difficult to identify. Moreover, it seems more interesting to have the unobserved heterogeneity in a parameter where the duration-dependence is taken also into account.

Thus, given an expression for the offer arrival rate with unobserved heterogeneity, $\alpha(t, \eta)$, we have that both reservation wages and hazard rates will depend on unobserved heterogeneity and so, we can call them respectively, $w_{R}(t, \eta)$ and $\phi(t, \eta) .^{7}$

With unobserved heterogeneity, the log-likelihood function takes the form:

$$
\ln £_{h}=\sum_{i=1}^{N} \sum_{t=1}^{d_{i}} \ln \int L(\eta) d F(\eta)
$$

where $F(\eta)$ is the cumulative distribution function of $\eta$, which is a discrete function with two mass points, $\eta_{1}$ and $\eta_{2}$. These mass points are selected in order to verify the assumption of $E(\eta)=0$ which is necessary given the presence of a constant term in the offer arrival rate. Besides, there is a probability $p$ for the variable $\eta$ to be equal to its value $\eta_{1}$.

The function $L(\eta)$ is the likelihood function described in the former subsection, where its arguments are all functions of the unobserved heterogeneity variable, $\eta$.

Hence, incorporating the referred notation, the log-likelihood function, $\ln £_{h}$, used in the estimation process is:

$$
\sum_{i=1}^{N} \sum_{t=1}^{d_{i}} \ln \left\{\left(\left[f_{W_{o}}\left(W_{o} \mid t\right) h_{i}\left(t, \eta_{1}\right)\right]^{v_{i}}\left[h_{i}\left(t, \eta_{1}\right)\right]^{1-v_{i}}\right)^{c_{i} y_{i t}}\left(1-h_{i}\left(t, \eta_{1}\right)\right)^{1-c_{i} y_{i t}} p\right.
$$

\footnotetext{
${ }^{7}$ Consequently, the grouped or discrete hazard rate would be $h(t, \eta)$.
} 


$$
\left.+\left(\left[f_{W_{o}}\left(W_{o} \mid t\right) h_{i}\left(t, \eta_{2}\right)\right]^{v_{i}}\left[h_{i}\left(t, \eta_{2}\right)\right]^{1-v_{i}}\right)^{c_{i} y_{i t}}\left(1-h_{i}\left(t, \eta_{2}\right)\right)^{1-c_{i} y_{i t}}(1-p)\right\}
$$

\subsection{Variables selected for the estimation}

The model has been estimated structurally using the monthly data described before and the assumption made in Subsection 3.2 that wages are lognormal. But the difficulties in the process of estimation make other simplifying assumptions necessary.

In the estimation, a monthly discount rate of $0.3 \%$ (i.e. a $3.66 \%$ annual rate) was imposed and not estimated and $T$ was set to 24 months in calculating the final condition for the reservation wage. Besides, the reservation wage differential equation, equation (6), is discretized in $T+1$ equations where $w_{R}^{\prime}(t) \simeq w_{R}(t+1)-w_{R}(t)$.

In the results I present, there are four explanatory variables. Skill, which is measured by the level of education: a skilled worker is one with education equal to or above secondary. Age, divided in three groups (less than 30 years old, Age1830; between 30 and 45 years old, Age3045; and more than 45 years old, Age4565). A variable which indicates if the individual receives or has received unemployment benefits, Benefits. And, lastly, a measure of the business cycle, Recession, which is a dummy variable taking the value 1 in the period between 1991:2 and 1994:2 (over which GDP grew by 0.68\%, as opposed to $3.91 \%$ over the rest of the sample period). These variables make for twenty-four types of workers, so I have to compute reservation wages only twenty-four times for each evaluation of the likelihood function and not for each individual in the sample. 
The variable Benefits requires further comment. It indicates not only whether the unemployed worker actually receives unemployment benefits or not, but also whether he has received them. In fact, this variable divides the sample into two groups of unemployed workers: those who have access to unemployment benefits and those that have not. The basic idea behind this distinction is that workers who have accumulated and used their entitlement to unemployment benefits have a different behavior in their search process than those without those rights. However, the empirical motivation for this distinction is different: to correctly estimate the effect of benefits on a structural estimation, we would need to know the complete sequence of benefit receipt over the spell of unemployment of each worker. Moreover, observation of the future sequence of benefits of unemployed workers who abandon the sample before exiting unemployment would be necessary. But these requirements are clearly far from being satisfied with the present estimation method and the data used. So, we have to follow an intermediate solution. This is the motivation of the two groups of workers described above. The effect of unemployment benefits estimated through this variable will not be correct in general but it seems that pooling those workers who have received and exhausted unemployment benefits with those who already receive them is less incorrect than pooling them with those who never have received unemployment benefits.

The following stage in the estimation exercise is to select a functional form for the parameters of the model. The selected functional forms are shown in Table 4 . The offer arrival rate, $\alpha(t)$, and the mean firing rate, $\delta^{*}$, are parameterized as having a normal density. Given that both are hazard 
rates, they can be represented using a probability distribution function. The other parameters are assumed to be exponential because of the assumption of lognormal wages, in order to reduce their scale or to restrict them to be non-negative. With respect to unobserved heterogeneity, $p$ is parameterized in order to be between 0 and 1 and the two mass points' parameterization satisfies the assumption $E(\eta)=0$.

Different specifications have been estimated and the estimation shown is the one providing the best results in terms of the likelihood function value and the standard errors of the estimated coefficients. In any event, the specification shown relies on the usual estimation of expected wages as dependent on skill and age. Less usual is the estimation of the other parameters, but we can think that the skill variable should affect the offer arrival rate and that unemployment benefits should not only make the value of time for the unemployed worker to be different but also that his search effort, reflected in the offer arrival rate, should differ from those without benefits. The mean firing rate is parameterized to depend on the variable Recession. The reason is not only the possible change in the firing rate over the business cycle but also to facilitate the identification of this important parameter of the model.

Descriptive statistics of the variables included in the estimation, accepted wages and the duration of unemployment spells are shown in Table 5 . These sample statistics show some important empirical facts. Firstly, skilled unemployed workers have a significantly higher mean accepted wage than unskilled ones. This fact can be due to both a higher mean in the distribution of offered wages or because their acceptance rule is more demanding, so they wait until a better offer is received. With respect to the distribution of wages across 
age, it shows a hump shape, with the maximum accepted wages being in the group of unemployed workers aged between 30 and 45 years old. If we turn to the duration of unemployment spells, we can see that unemployed workers with durations below the mean are those aged between 30 and 45 years old, the skilled and, especially, those without unemployment benefits. Finally, if we look at censored spells, we can see that censoring is especially important for unemployed workers above 45 years old and those with unemployment benefits. This final observation reinforces the former one of a lower duration for individuals without unemployment benefits.

\subsection{Results}

The main results of the structural estimation can be seen in Tables 6 and 7 . Table 6 shows the estimated coefficients of the model both when unobserved heterogeneity is and is not controlled for. Table 7 reports the predicted values of the main elements of the model, for the sample mean values of the regressors and both for skilled and unskilled workers and for workers with and without unemployment benefits.

First, duration dependence is estimated in the offer arrival rate, $\alpha(t)$, and in the value of time for unemployed workers, $b(t)$. We can observe that there is a strong negative duration dependence in both parameters: a $6 \%$ monthly decrease in $b(t)$ and a $13.05 \%$ mean monthly decrease in $\alpha(t)$. Both parameters are highly significant despite unobserved heterogeneity being controlled for.

With respect to the skill variable, we can see that it is quite significant in both the offer arrival rate and in mean offered wages. There are more 
offers for skilled unemployed workers and the offered wages are quite higher for these workers.

The effect of unemployment benefits is very strong not only in the value of time for the unemployed worker but also in the offer arrival rate which is much lower for workers with unemployment benefits (see Table 7). These results might be revealing a lower search effort of this type of workers, reflected in a lower offer arrival rate but also on a higher valuation of time. What is important is that the known stylized fact of lower hazard rates of workers with unemployment benefits can be interpreted much better within this structural estimation. We should not to forget, however, that the estimation is not totally structural with respect to this variable and so, we have to be cautious in interpreting this result.

The other explanatory variable is not so important as former: there is only a small effect of age on the mean offered wage, showing the same hump shape as accepted wages show in the sample.

The estimated values of $\alpha(t)$ and $E(w)$ are quite reasonable: the offer arrival rate at the sample mean values of the regressors begins at $27.84 \%$ in the first month of unemployment and has a value of only $4.07 \%$ fourteen months later. This parameter is higher for skilled unemployed workers: $36.96 \%$ in the first month and $6.84 \%$ in the fourteenth. The estimated mean of offered wages, $E(w)$, at the sample mean of the regressors, is 112,999 pesetas, around 864 dollars per month (at the December 1996 exchange rate), which is only $8.8 \%$ lower than the mean monthly accepted wage in the sample (see Table 5). Finally, the value of the parameter $b(t)$ is estimated to be very high, although it has a rapid decrease over the spell of unemployment. 
However, it is still more than three times larger than the reservation wage along the studied fourteen months of the unemployment spell. Remember that $b(t)$ includes all the income the individual can have access to, plus his valuation of time in unemployment, which can be very high, at least in the first months of unemployment. Moreover, we have to take into account the entitlement effect referred to in the theoretical section. This effect, as will be illustrated below, makes the reservation wage be highly decreasing and so, it can be much lower than the value of unemployment time along all the spell of unemployment. However, again, the incorrectly estimated effect of unemployment benefits can be contaminating this result.

There exists a problem with the estimation of the variance of the offered wage and of the measurement error. In fact, real variation of offered wages is estimated to be too low: the estimated fraction of the wage variance accounted for by real variation of wages is of only $7.58 \%$. Essentially, more than $90 \%$ of the variation in wages is due to measurement error. Although measurement error is present in our data, due to the construction procedure, this unexpected result may be reflecting problems of identification which have also appeared in other structural estimations like Eckstein and Wolpin (1990). Nevertheless, the total variation of wages, $\sigma_{u}+\sigma_{\varepsilon}$, is estimated quite well: the coefficient of variation of accepted wages is $39.45 \%$ and the estimated coefficient of variation of observed wages is $41.98 \%$.

Finally with respect to the mean firing rate, the estimates are $1.89 \%$ per month for the no-recession period, and $0.55 \%$ in the recession one. The coefficient associated with Recession is estimated to be negative, which could seem quite surprising, but we have to take into account that this firing rate 
is reflecting not only the firing flow from employment to unemployment but also, contract expirations and, even, a component of quitting. Nevertheless, this variable plays an important role in the identification of this parameter, since without it, the mean firing rate is estimated with a high standard error.

Estimated reservation wages and hazard rates can be obtained given these estimated parameters. Reservation wages are decreasing with unemployment duration (See Figure 3), as the theoretical model predicts, and higher for skilled unemployed workers (137,481 pesetas for skilled workers, i.e. 1,052 dollars, and 114,465 pesetas, 876 dollars, for the unskilled ones in the first month of unemployment). But the main characteristic of reservation wages is that they are very low: for sample mean values of the regressors, the reservation wage in the first month of unemployment is only $2.63 \%$ higher than the mean of the distribution of wages and, after 14 months of unemployment, the reservation wage is $55.75 \%$ lower than it was in the first month. This fall is larger for unskilled workers $(56.4 \%)$ than for skilled workers $(43.2 \%)$. The effect of the firing rate on reservation wages, via the entitlement effect, is present and very important. Comparing with a no-firing situation, the decrease in reservation wages is more than 5 times larger, so the prediction of the theoretical model of reservation wages being highly decreasing because of this entitlement effect is supported by the estimation.

Reservation wages for workers with and without unemployment benefits show some surprising results. Although at the beginning of the spell, reservation wages are $5.1 \%$ higher for workers with unemployment benefits, this result turns to be different for the third month on unemployment onwards (See Figure 3). This change is due to the presence of firing and so, to the en- 
titlement effect: as time passes, an unemployed worker with unemployment benefits realizes that as soon as he accepts an offer, in case of a future firing, he will have access to the high level of income of the beginning of the present spell. However, this effect has to be taken with not so much confidence because it is obviously overestimated due to, apart from the problems referred to above, the problem of shortsightedness present in this estimation: a worker who has received unemployment benefits in one spell of unemployment solves the reservation wage equation as if he would received those benefits in the future spell of unemployment.

The estimated low reservation wages lead to high acceptance probabilities: after 4 months, they are practically equal to one (See Figure 4). However, the acceptance probability begins at a low level, $19.37 \%$ at the beginning of the spell, basically because the offer arrival rates are quite high in these first months. But it grows rapidly, reaching the value of one in 4 months. There are some differences between skilled and unskilled workers and between workers with and without unemployment benefits, again because acceptance probabilities are bigger for the unskilled and for those without unemployment benefits, which is sensible given their lower reservation wages.

The final result of this estimation is the hazard rate. This rate is the product of the offer arrival rate and the acceptance probability. As shown in Figures 5 and 6 , the hazard rate increases until between 2 to 4 months and then it decreases, becoming equal to the offer arrival rate, as the acceptance probability approaches one. The initial increase in the hazard is due to the large increase in the acceptance probabilities. When we look at hazard rates by skill (Figure 6), surprisingly, the hazards of the unskilled unemployed 
workers are slightly higher in the first 3 months than those of the skilled ones. This fact is due to their higher acceptance probabilities. In the early stages of unemployment, the acceptance of offers is the dominant factor at work while in later stages, the offer arrival rate becomes the only determinant of the hazard. Due to the higher probability of offers arriving for skilled unemployed workers, these individuals have higher hazard rates for durations of more than four months.

The hazard rate for workers with and without unemployment benefits are, as shown in Figure 5, very different. The known stylized fact estimated in some reduced-form estimations is obtained also here: a worker without unemployment benefits has higher probabilities of exiting unemployment in all of the fourteen months of the spell which are studied here. The difference in probability starts being much larger for those without unemployment benefits than for those with them and, at the fourteenth month in unemployment, the hazard continues being almost two times larger (See Table 7). But with the structural estimation carried out, we can interpret this result and conclude that in the early stage of the spell, the main element at work is the acceptance probability, which is much larger for those without unemployment benefits, but, once this probability is estimated to be equal to one, the difference between the two groups of workers remains because the offer arrival rate is still quite higher for those without benefits.

Finally we can see in Table 6 that the effect of unobserved heterogeneity does not provoke the duration dependence to be estimated with more error. Moreover, the estimated a effect of unobserved heterogeneity on the offer arrival rate is not very significant: the $t$-ratio of the first value of the 
unobserved heterogeneity variable is 0.64 . The probability of this value is estimated to be 0.86. Finally, we can see that controlling for unobserved heterogeneity does not change the effect of the rest of explanatory variables.

To conclude, the estimation of the search model shows that Spanish unemployed workers do not differ so much from unemployed workers elsewhere: their acceptance probabilities are very high (See Wolpin, 1987 for US data or Van den Berg, 1990 for the Netherlands). Thus, the main mechanism at play in the process of exit from unemployment is the arrival of offers from employers. The offer arrival rate, in spite of its initial high values, is very low for workers who are unemployed for more than 12 months, the so-called longterm unemployed. Thus, these group of unemployed workers, among with the unskilled ones, have serious problems in order to leave unemployment in Spain.

\section{Conclusions}

In this paper, the non-stationary job search model of Van den Berg (1990) is extended by introducing a firing rate. When the unemployed worker is looking for a new job, he takes into consideration that once employed he can be fired again. This future risk makes him reduce his reservation wages because if he is fired in the future, he will be unemployed again but, given the nonstationarity of the process, he will have access to higher chances of re-employment and he will enjoy an improved situation than at present. In a nutshell, there is an entitlement effect, which makes unemployed workers be less demanding in accepting offers.

The main objective of this paper is, however, to implement a structural 
estimation of this model of search for the Spanish economy. The estimation methodology is somewhat novel, because it is carried out using grouped data: we estimate a continuous model using data which are observed in discrete intervals so we have to develop the likelihood function for this kind of data, which is very common in the case of unemployment spell data bases. Besides, the model is estimated by allowing the presence of unobserved heterogeneity in a very general way: the Heckman and Singer (1984) mixture technique.

One of the basic results of the estimation of the search model is that the re-employment probability, the hazard rate, is increasing up to between the second and the fourth month of the unemployment spell, but then it becomes clearly decreasing. And this result is obtained once we control for the presence of unobserved heterogeneity. The interpretation of this result is that in the first months of unemployment, the main element at work is the rapid increase of the acceptance probability, given the low levels and the decreasing pattern of reservation wages. The decrease of reservation wages is much larger than in a no-firing situation, so we can conclude that the entitlement effect of the firing rate is supported by the estimation results. But as soon as these first months pass, the only element present in the hazard rate is the offer arrival rate, because the acceptance probabilities are, in fact, equal to one.

As the second main result, we obtain that there are some important differences between skilled and unskilled unemployed workers: the offer arrival rate and the mean of the distribution of offered wages are quite higher for the former. This fact makes, however, acceptance probabilities of unskilled workers be higher than those of skilled ones and so, in the first few months, 
the estimated hazard rates for unskilled unemployed workers are a bit higher than that for skilled ones. For the following months, the skilled unemployed workers have more opportunities of exiting from unemployment.

It has been obtained also that the workers who receives or has received unemployment benefits has a much lower probability of exiting unemployment. The reason differs between the early stages of unemployment and the latter ones: at first, the reason is that those with unemployment benefits have higher reservation wages and so, lower acceptance probabilities but, from the fourth month of unemployment onwards, the only difference is in the offer arrival rates, which are much higher for those without unemployment benefits, possibly because they have a higher search effort than those without such benefits.

Finally we can assert that the so-called long-term unemployed, those who are unemployed for more than a year, have very small probabilities of exiting unemployment: this is estimated to be less than $4 \%$ per month for the fourteenth month in unemployment. This result is consistent with the fact that more than $50 \%$ of Spanish unemployed workers are long-term unemployed, and, given that the acceptance probability is estimated to be equal to one in this stage of unemployment, we can conclude that the problem with these workers is that they do not receive almost any offer once they spend more than a year in unemployment. 


\section{Appendix A}

The proof of Theorem 1 consists of: (1) proving the following Lemma which, basically, requires that $w_{R}^{0 \prime}(t)<0$ for $(i)$ and $(i i)$ to hold, and (2) proving that $w_{R}^{0 \prime}(t)<0$.

Lemma 2 If assumptions (A1)-(A7) are satisfied and if, for every $t \in[0, T)$, we have that $w_{R}^{0 \prime}(t)<0$, then:

$$
\begin{aligned}
& \text { (i) } w_{R}(t)<w_{R}^{0}(t) \text {, } \\
& \text { (ii) } w_{R}^{\prime}(t)<0 .
\end{aligned}
$$

Proof : Suppose that at some $t \in[0, T) w_{R}(t) \geq w_{R}^{0}(t)$ holds. Then, because of the relationship between $w_{R}(t)$ and $w_{R}^{0}(t)$ we will have that $w_{R}^{\prime}(t)>$ 0 . However, given that $w_{R}(t)$ and $w_{R}^{0}(t)$ are continuous functions and, by the Lemma's assumptions, $w_{R}^{0 \prime}(t)<0$, it cannot be true that $w_{R}(T)=w_{R}^{0}(T)$, which must be verified at time $T$ given the assumptions of the model. Thus, the opposite must hold: $w_{R}(t)<w_{R}^{0}(t)$ and implied be this, that $w_{R}^{\prime}(t)<0$. Q.E.D.

Now we have to prove that $w_{R}^{0}(t)$ is a decreasing function of $t$ under all the assumptions (K1)-(K4). The proofs under each of the them are quite similar so we will show only the proof under (K1), i.e. for $b(t)$ :

Given (8) we will have that:

$w_{R}^{0}(t)-w_{R}^{0}(t+\tau)-\frac{\alpha(t)}{\rho}\left(G\left(w_{R}^{0}(t), t\right)-G\left(w_{R}^{0}(t+\tau), t\right)\right)=\frac{\delta^{*}+\rho}{\rho}(b(t)-b(t+\tau))$ where $G\left(w_{R}^{0}(t), t\right)=\int_{w_{R}^{0}(t)}^{\infty}\left(w-w_{R}^{0}(t)\right) d F(w, t)$.

If $b(t)$ is decreasing in $t$, the right-hand side of this expression will be positive and since the function $w_{R}^{0}(t)-\frac{\alpha(t)}{\rho} G\left(w_{R}^{0}(t), t\right)$ is a increasing function 
of $w_{R}^{0}(t)$, we will have that $w_{R}^{0}(t)>w_{R}^{0}(t+\tau)$, that is $w_{R}^{0}(t)$ is decreasing in the time the worker is unemployed.

If we allow for all the assumptions to hold, we will obtain a decreasing $w_{R}^{0}(t)$ also:

$$
\begin{aligned}
& w_{R}^{0}(t)-w_{R}^{0}(t+\tau)-\frac{\alpha(t+\tau)}{\rho}\left(G\left(w_{R}^{0}(t), t+\tau\right)-G\left(w_{R}^{0}(t+\tau), t+\tau\right)\right) \\
= & \frac{\delta^{*}+\rho}{\rho}(b(t)-b(t+\tau))+\frac{G\left(w_{R}^{0}(t), t+\tau\right)}{\rho}(\alpha(t)-\alpha(t+\tau)) \\
& +\frac{\alpha(t)}{\rho}\left(G\left(w_{R}^{0}(t), t\right)-G\left(w_{R}^{0}(t), t+\tau\right)\right)
\end{aligned}
$$

That is so because all the terms in the right-hand side of this expression are positive and because $w_{R}^{0}(t)-\frac{\alpha(t+\tau)}{\rho} G\left(w_{R}^{0}(t), t+\tau\right)$ is an increasing function of $w_{R}^{0}(t)$. So $w_{R}^{0}(t)$ will be decreasing under (K1)-(K4) taken together, and so, $w_{R}(t)$ will be always a decreasing function of the time the worker is unemployed.

\section{Appendix B}

To obtain monthly wages, the labor income and the unemployment benefits declared in the correspondent quarter have been compared. If there are no unemployment benefits, the monthly wage is the declared labor income divided by three. If there are unemployment benefits, their amount is compared with the labor income: if the benefits are bigger than $80 \%$ of the labor income ( $70 \%$ for periods posterior to $1992: 2$ ), then the monthly wage is the total amount declared as labor income. On the contrary, the monthly wage is the labor income divided by two. This rule is based on the characteristics of 
the unemployment benefits system in Spain, which lowered the replacement rate from $80 \%$ of the previous wage to $70 \%$ in the second quarter of 1992 .

Calculation of monthly duration data is more difficult. The numbers of months of unemployment in the spell can be computed once it is established how many months of unemployment there are in the first quarter of unemployment and, if the worker exits unemployment, how many months he has been employed in the first quarter of employment. The general rule applied to compute the number of unemployment months in these two quarters is based on comparing the labor income of each quarter, if it is positive, with the unemployment benefits received that quarter or with the labor income of the following quarter. If there is no labor income in the first quarter the individual answers he is unemployed, it is considered that he is unemployed during all the quarter. If the reported labor income is low enough a duration of two months is imputed in the correspondent quarter but if this income is sufficiently large, it is considered that the worker has been only one month in unemployment in that quarter. 


\section{References}

[1] Atkinson A. and J. Micklewright, J. (1991), "Unemployment Compensation and Labor Market Transitions: A Critical Review". Journal of Economic Literature, 29, 1679-1727.

[2] Berkovitch E. (1990), "A Stigma Theory of Unemployment Duration" in: Y. Weiss and G. Fishelson, eds., Advances in the Theory and Measurement of Unemployment (Macmillan, London), 20-56.

[3] Bover, O., M. Arellano and S. Bentolila (1997), "Unemployment Duration, Benefit Duration and the Business Cycle", CEMFI Working Paper 9717.

[4] Devine T. J. and N. M. Kiefer (1991), Empirical Labor Economics: The Search Approach, Oxford University Press, New York.

[5] Eckstein Z. and K. Wolpin (1990), "Estimating a Market Equilibrium Search Model from Panel Data on Individuals", Econometrica, 58-4, 783-808.

[6] Garcia-Perez, J. I. (1997), "Las Tasas de Salida del Empleo y el Desempleo en España (1978-1993)", Investigaciones Económicas, XXI(1), $29-53$.

[7] Heckman, J. and B. Singer (1984), "A Method for Minimizing the Impact of Distributional Assumptions in Econometric Models for Duration Data", Econometrica, 52, 271-320. 
[8] Hey, J. D. and K.G. Mavromaras, (1981), "The Effect of Unemployment Insurance on the Riskiness of Occupational Choice", Journal of Public Economics, 16, 317-341.

[9] Jenkins, S. (1995), "Easy Estimation Methods for Discrete-Time Duration Models", Oxford Bulletin of Economics and Statistics, 120-138.

[10] Lancaster, T. and A. Chesher (1983), "An Econometric Analysis of Reservation Wages", Econometrica, 51, 1661-1676.

[11] Meyer, B. (1990), "Unemployment Insurance and Unemployment Spells", Econometrica, 58, 757-782.

[12] Miller, R. (1984), "Job Matching and Occupational Choice", Journal of Political Economy, 92, 1086-1120.

[13] Mortensen, D. (1986), "Job Search and Labor Market Analysis", in: Ashenfelter, O. C. and Layard, R.,eds.,Handbook of Labor Economics, North-Holland, Amsterdam (Vol. II), 849-919.

[14] Narendranathan W. and S. Nickell (1985), "Modelling the Process of Job Search", Journal of Econometrics, 28, 29-49.

[15] Narendranathan W. and M. Stewart (1993), "How Does the Benefit Effect Vary as Unemployment Spells Lengthen?", Journal of Applied Econometrics, 8, 361-381.

[16] Usategui, J.M. (1993), "Finite Duration of Unemployment Insurance, Reservation Wages and Participation in the Job Market", Journal of Public Economics, 50, 407-427. 
[17] Van den Berg, G. J. (1990), "Nonstationarity in Job Search Theory", Review of Economic Studies, 57, 255-277.

[18] Vishwanath T. (1989), "Job Search, Stigma Effect, and Escape Rate from Unemployment" Journal of Labor Economics, 7-4, 487-502.

[19] Wolpin, K. I. (1987), "Estimating a Structural Search Model: The Transition from School to Work", Econometrica, 55(4), 852-874.

[20] Wright, R. D. (1987): "Search, Layoffs, and Reservation Wages", Journal of Labor Economics, 5-3, 354-365. 
Table 1

Effects of a $10 \%$ increase in each parameter on reservation wages and on the hazard rates

\begin{tabular}{|c|c|c|c|c|c|c|}
\hline \multirow[t]{2}{*}{ Change in: } & \multicolumn{3}{|c|}{ Reservation Wages } & \multicolumn{3}{|c|}{ Hazard Rates } \\
\hline & $\mathbf{w}_{R}(\mathbf{1})$ & $\overline{\mathbf{w}_{R}(\mathbf{1 2})}$ & $\mathbf{w}_{R}(24)$ & $\phi(\mathbf{1})$ & $\phi(12)$ & $\phi(24)$ \\
\hline$b(t)=e^{b_{0}+b_{1} \times t}$ & & & & & & \\
\hline $\mathbf{b}_{0}$ & 2.21 & -1.15 & -7.51 & -2.00 & 0.21 & 0.01 \\
\hline $\mathbf{b}_{1}$ & 1.39 & 2.39 & 0.30 & -1.26 & -0.46 & 0.00 \\
\hline$\alpha(t)=e^{a_{0}+a_{1} \times t}$ & & & & & & \\
\hline $\mathbf{a}_{0}$ & 5.16 & 11.2 & 28.58 & 4.89 & 7.42 & 9.91 \\
\hline $\mathbf{a}_{1}$ & 1.08 & 4.51 & 17.82 & -0.98 & 0.22 & 2.29 \\
\hline$E(w, t)=e^{e_{0}+e_{1} \times t}$ & & & & & & \\
\hline $\mathbf{e}_{0}$ & 7.79 & 11.15 & 17.5 & 1.82 & -0.20 & -0.01 \\
\hline $\mathbf{e}_{1}$ & 0.59 & 2.25 & 7.66 & -0.53 & -0.21 & -0.01 \\
\hline $\operatorname{Var}(w, t)=e^{v_{0}+v_{1} \times t}$ & & & & & & \\
\hline $\mathbf{v}_{0}$ & 0.30 & -0.41 & -1.26 & -4.62 & -1.86 & -0.03 \\
\hline $\mathbf{v}_{1}$ & 0.01 & -0.01 & -0.06 & -0.01 & -0.31 & -0.01 \\
\hline$\delta(s)=d_{0}+e^{d_{1}+d_{2} \times s}$ & & & & & & \\
\hline $\mathbf{d}_{0}$ & -0.98 & -3.87 & -11.61 & 0.88 & 0.68 & 0.01 \\
\hline $\mathbf{d}_{1}$ & -2.48 & -9.98 & -30.00 & 2.24 & 1.62 & 0.01 \\
\hline $\mathbf{d}_{2}$ & -1.12 & -4.44 & -13.32 & 1.01 & 0.78 & 0.01 \\
\hline
\end{tabular}

Note: The values are the changes in the reservation wage and the hazard rate, respectively, at $i$ months into the unemployment spell.

The baseline is: $r=0.003, T=84, b(0)=120, b^{\prime}(t)=-0.1, \alpha(0)=$ $0.07, \alpha^{\prime}(t)=-0.01, E(w, 0)=150, E^{\prime}(w, t)=-0.005, C V(w)=60 \%$, $\operatorname{Var}^{\prime}(w, t)=-0.03, \delta(0)=0.1, \delta^{\prime}(t)=-0.05$. 
Table 2

Effects of the firing rate on reservation wages

\begin{tabular}{|c|c|c|c|c|c|c|}
\hline \multicolumn{4}{|c|}{ Values of the parameters: } & \multirow[t]{2}{*}{$\mathbf{w}_{R}(\mathbf{1})$} & \multirow{2}{*}{$\begin{array}{c}\text { Period when } \\
\mathbf{w}_{R}(\mathbf{t})=\mathbf{0}\end{array}$} & \multirow{2}{*}{$\frac{\mathbf{w}_{R}(\mathbf{1 8})-\mathbf{w}_{R}(\mathbf{1})}{\mathbf{w}_{R}(\mathbf{1})}$} \\
\hline $\mathbf{d}_{0}$ & $\mathbf{d}_{1}$ & $\mathbf{d}_{2}$ & $\boldsymbol{\delta}^{*}($ in $\%)$ & & & \\
\hline 0 & 0 & 0 & 0 & 163 & - & -15.76 \\
\hline 0.04 & 0 & 0 & 4 & 101 & 44 & -53.58 \\
\hline 0.08 & 0 & 0 & 8 & 84 & 17 & -100.00 \\
\hline 0 & 0.04 & -0.01 & 3.02 & 104 & 66 & -43.13 \\
\hline 0 & 0.04 & -0.05 & 0.45 & 143 & - & -20.01 \\
\hline 0 & 0.08 & -0.01 & 6.98 & 81 & 22 & -90.23 \\
\hline 0 & 0.08 & -0.05 & 1.41 & 122 & - & -28.16 \\
\hline 0.01 & 0.04 & -0.01 & 3.34 & 101 & 58 & -46.35 \\
\hline 0.01 & 0.04 & -0.05 & 1.83 & 116 & - & -31.79 \\
\hline 0.01 & 0.08 & -0.01 & 7.15 & 80 & 22 & -92.53 \\
\hline 0.01 & 0.08 & -0.05 & 3.57 & 99 & 53 & -48.73 \\
\hline 0.03 & 0.04 & -0.01 & 3.81 & 99 & 53 & -49.03 \\
\hline 0.03 & 0.04 & -0.05 & 3.44 & 106 & 81 & -40.37 \\
\hline 0.03 & 0.08 & -0.01 & 7.44 & 79 & 21 & -94.60 \\
\hline 0.03 & 0.08 & -0.05 & 5.61 & 91 & 37 & -62.26 \\
\hline
\end{tabular}

Note: The firing rate is parameterized as $\delta(s)=d_{0}+d_{1} e^{d_{2} \times s} . \delta^{*}$ is the corresponding mean firing rate. The variables shown are: the reservation wage in the first period of unemployment, $w_{R}(1)$, its rate of change in the first 18 periods, $\frac{w_{R}(18)-w_{R}(1)}{w_{R}(1)}$, and the period, if it exists, when the reservation wage becomes equal to zero, $w_{R}(t)=0$.

The value for the remaining parameters are the same as in Table 1. 
Table 3

Distribution of unemployment duration and others variables in the sample

\begin{tabular}{|c|c|c|c|c|}
\hline & \multicolumn{2}{|c|}{ Completed Spells } & \multicolumn{2}{|c|}{ Censored Spells } \\
\hline & Number & Percentage & Number & Percentage \\
\hline Months & & & & \\
\hline $0-1$ & 83 & 11.59 & 88 & 13.31 \\
\hline $1-2$ & 94 & 11.72 & 84 & 12.71 \\
\hline $2-3$ & 158 & 19.70 & 113 & 17.09 \\
\hline $3-4$ & 135 & 16.83 & 55 & 8.32 \\
\hline $4-5$ & 100 & 11.47 & 33 & 4.99 \\
\hline $5-6$ & 60 & 7.48 & 64 & 9.68 \\
\hline $6-7$ & 36 & 4.49 & 17 & 2.57 \\
\hline $7-8$ & 44 & 5.48 & 10 & 1.51 \\
\hline $8-9$ & 24 & 2.99 & 32 & 4.84 \\
\hline $9-10$ & 20 & 2.49 & 21 & 3.17 \\
\hline $10-11$ & 19 & 2.37 & 8 & 1.21 \\
\hline $11-12$ & 10 & 1.25 & 30 & 4.54 \\
\hline $12-13$ & 11 & 1.37 & 17 & 2.57 \\
\hline $13-14$ & 5 & 0.62 & 9 & 1.36 \\
\hline $14-15$ & 3 & 0.37 & 80 & 12.10 \\
\hline Age1830 & 119 & 12.98 & 77 & 11.65 \\
\hline Age3045 & 396 & 47.95 & 258 & 39.03 \\
\hline Skill & 52 & 6.48 & 59 & 8.93 \\
\hline With benefits & 498 & 62.09 & 443 & 67.02 \\
\hline Recession time & 223 & 27.80 & 182 & 27.53 \\
\hline TOTAL & 802 & & 661 & \\
\hline
\end{tabular}


Table 4

\section{Functional forms of the estimated parameters}

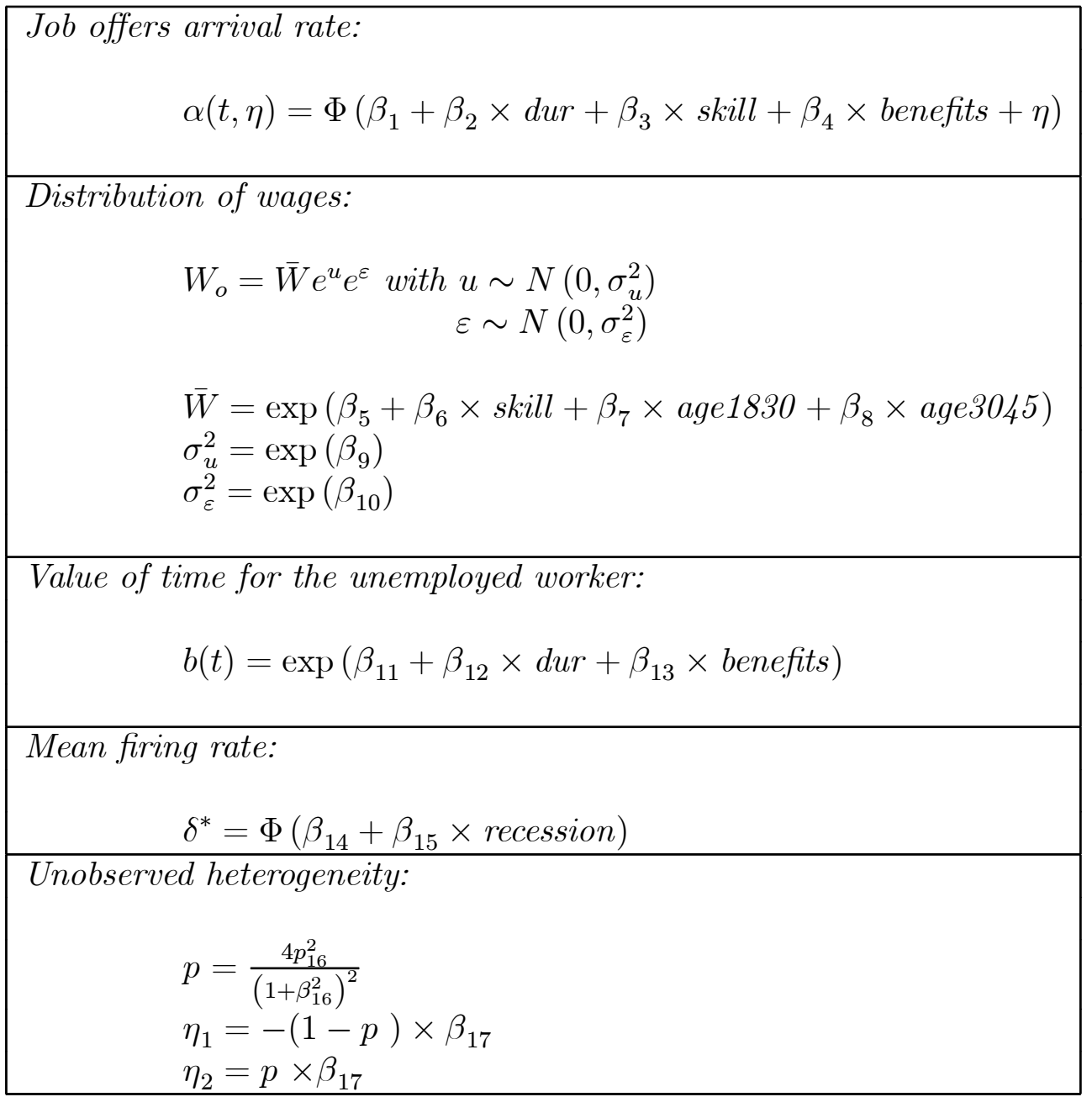


Table 5

Duration and monthly accepted wages: distribution

\begin{tabular}{|l|r|r|r|r|r|r|}
\hline & \multicolumn{3}{|c|}{ Completed Spells } & \multicolumn{3}{|c|}{ Censored Spells } \\
\cline { 2 - 7 } & \multicolumn{1}{|c|}{ Mean } & $\begin{array}{r}\text { Standard } \\
\text { deviation }\end{array}$ & Median & Mean & $\begin{array}{r}\text { Standard } \\
\text { deviation }\end{array}$ & Median \\
\hline \hline & & & & & & \\
Duration of spells: & & & & & & \\
Full Sample & $\mathbf{3 . 6 8}$ & $\mathbf{2 . 9 4}$ & $\mathbf{3}$ & $\mathbf{5 . 1 3}$ & $\mathbf{4 2}$ & $\mathbf{3}$ \\
Age1830 & 3.78 & 2.97 & 3 & 4.48 & 4.43 & 3 \\
Age3045 & 3.53 & 2.79 & 3 & 4.33 & 4.42 & 2 \\
Age4565 & 3.83 & 3.12 & 3 & 5.91 & 4.88 & 5 \\
Skill & 3.33 & 2.43 & 3 & 4.51 & 4.15 & 3 \\
Unskilled & 3.70 & 2.97 & 3 & 5.19 & 4.77 & 3 \\
With Benefits & 4.54 & 3.01 & 4 & 6.55 & 4.74 & 5 \\
Without Benefits & 2.26 & 2.18 & 2 & 2.24 & 3.07 & 1 \\
Expansion & 3.58 & 2.87 & 3 & 4.84 & 4.65 & 3 \\
Recession & 3.92 & 3.10 & 3 & 5.88 & 4.81 & 5 \\
Monthly wages: & & & & & & \\
Full Sample & $\mathbf{1 2 3 , 9 0 6}$ & $\mathbf{4 8 , 8 8 1}$ & $\mathbf{1 1 7 , 0 8 4}$ & & & \\
Age1830 & 121,396 & 46,680 & 117,084 & & & \\
Age3045 & 128,822 & 49,457 & 124,275 & & & \\
Age4565 & 119,115 & 48,855 & 112,446 & & & \\
Skill & 161,676 & 79,558 & 131,807 & & & \\
Unskilled & 121,839 & 45,895 & 116,464 & & & \\
With Benefits & 123,362 & 45,069 & 118,661 & & & \\
Without Benefits & 124,822 & 54,842 & 115,846 & & & \\
Expansion & 120,740 & 48,673 & 114,054 & & & \\
Recession & 132,117 & 48,667 & 127,945 & & & \\
\hline
\end{tabular}


Table 6

Main results of the structural estimation

\begin{tabular}{|c|c|c|c|c|}
\hline & \multicolumn{2}{|c|}{ Without Unobs. Heterog. } & \multicolumn{2}{|c|}{ With Unobs. Heterog. } \\
\hline Parameter & Coefficient & t-ratio & Coefficient & t-ratio \\
\hline$\overline{\boldsymbol{\alpha}_{i}(\mathbf{t})}$ & & & & \\
\hline Constant & -0.243 & -1.977 & -0.263 & -2.295 \\
\hline Duration & -0.083 & -8.579 & -0.082 & -6.786 \\
\hline Skill & 0.303 & 1.990 & 0.274 & 2.353 \\
\hline Benefits & -0.414 & -3.948 & -0.439 & -4.413 \\
\hline$\overline{\mathbf{W}}_{i}$ & & & & \\
\hline Constant & 11.595 & 318.345 & 11.582 & 364.481 \\
\hline Skill & 0.112 & 1.589 & 0.155 & 2.065 \\
\hline Age18-29 & 0.032 & 1.353 & 0.065 & 1.988 \\
\hline Age30-45 & 0.048 & 1.759 & 0.082 & 2.355 \\
\hline$\sigma_{\mathrm{u}}^{2}$ & & & & \\
\hline Constant & -6.276 & -4.953 & -6.9773 & -6.319 \\
\hline$\sigma_{\varepsilon}^{2}$ & & & & \\
\hline Constant & -1.814 & -30.024 & -1.824 & -30.059 \\
\hline $\mathbf{b}_{i}(\mathbf{t})$ & & & & \\
\hline Constant & 12.112 & 42.832 & 12.238 & 44.765 \\
\hline Duration & -0.041 & -1.808 & -0.063 & -2.421 \\
\hline Benefits & 0.416 & 1.830 & 0.661 & 2.550 \\
\hline$\delta^{*}$ & & & & \\
\hline Constant & -1.9122 & -5.529 & -2.075 & -6.580 \\
\hline Recession & -0.331 & -3.281 & -0.467 & -2.562 \\
\hline $\begin{array}{l}\text { Unobs. Heterog. } \\
\eta_{1}\end{array}$ & & & 0.082 & 0.641 \\
\hline$p$ & & & 0.857 & 10.322 \\
\hline Log-likelihood & & & $-7,5^{\prime}$ & \\
\hline No. of observations & & & $7, \xi$ & \\
\hline
\end{tabular}


Table 7

Predicted values for the main elements of the model

\begin{tabular}{|l|r|r|r|r|r|}
\hline & Mean Values & Skilled & Unskilled & Benefits & No Benefits \\
\hline & & & & & \\
$\alpha(0)$ & 27.84 & 36.96 & 27.20 & 24.73 & 40.35 \\
$\alpha(14)$ & 4.07 & 6.84 & 3.91 & 3.33 & 8.09 \\
$1-F\left(w_{R}(0)\right)$ & 19.37 & 4.18 & 21.29 & 3.08 & 40.50 \\
$1-F\left(w_{R}(14)\right)$ & 100 & 100 & 100 & 100 & 100 \\
$\phi(0)$ & 5.39 & 1.55 & 5.79 & 0.76 & 16.34 \\
$\phi(14)$ & 4.07 & 6.34 & 3.91 & 3.33 & 8.09 \\
\hline & & & & & \\
$b(0)$ & 346,478 & 346,478 & 346,478 & 400,152 & 206,509 \\
$b(14)$ & 144,030 & 144,030 & 144,030 & 166,342 & 85,845 \\
$E(w)$ & 112,999 & 131,017 & 108,987 & 112,999 & 112,999 \\
$\operatorname{Var}(w)$ & 3,452 & 3,986 & 3,414 & 3,452 & 3,452 \\
$w_{R}(0)$ & 115,967 & 137,481 & 114,465 & 119,581 & 113,778 \\
$w_{R}(14)$ & 51,309 & 78,107 & 49,950 & 56,797 & 63,584 \\
\hline
\end{tabular}

Notes : The first six rows are percentages and the following ones are expressed in 1996 pesetas. The prediction is carried out using the model with unobserved heterogeneity. 
Figure 1: Kaplan-Meier estimates of the hazards

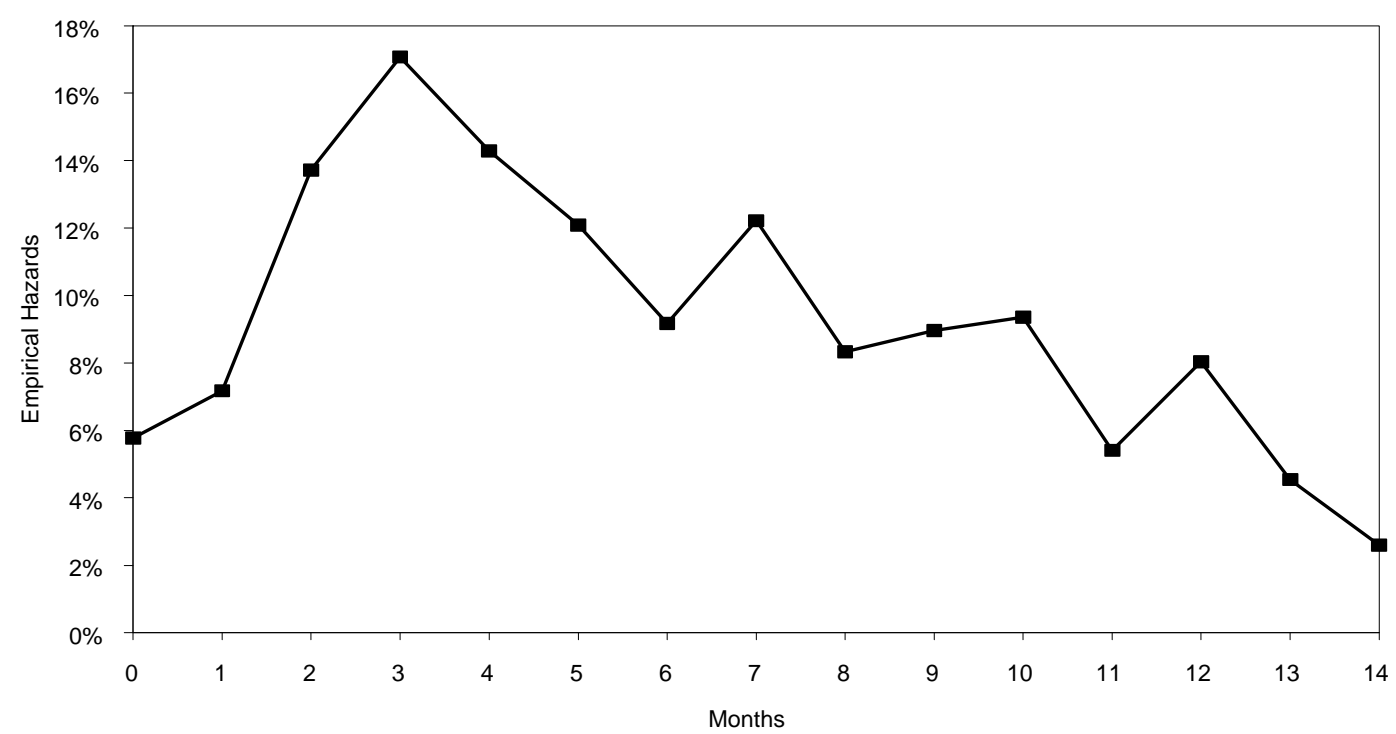


Figure 2: Histogram of the reemployment wages

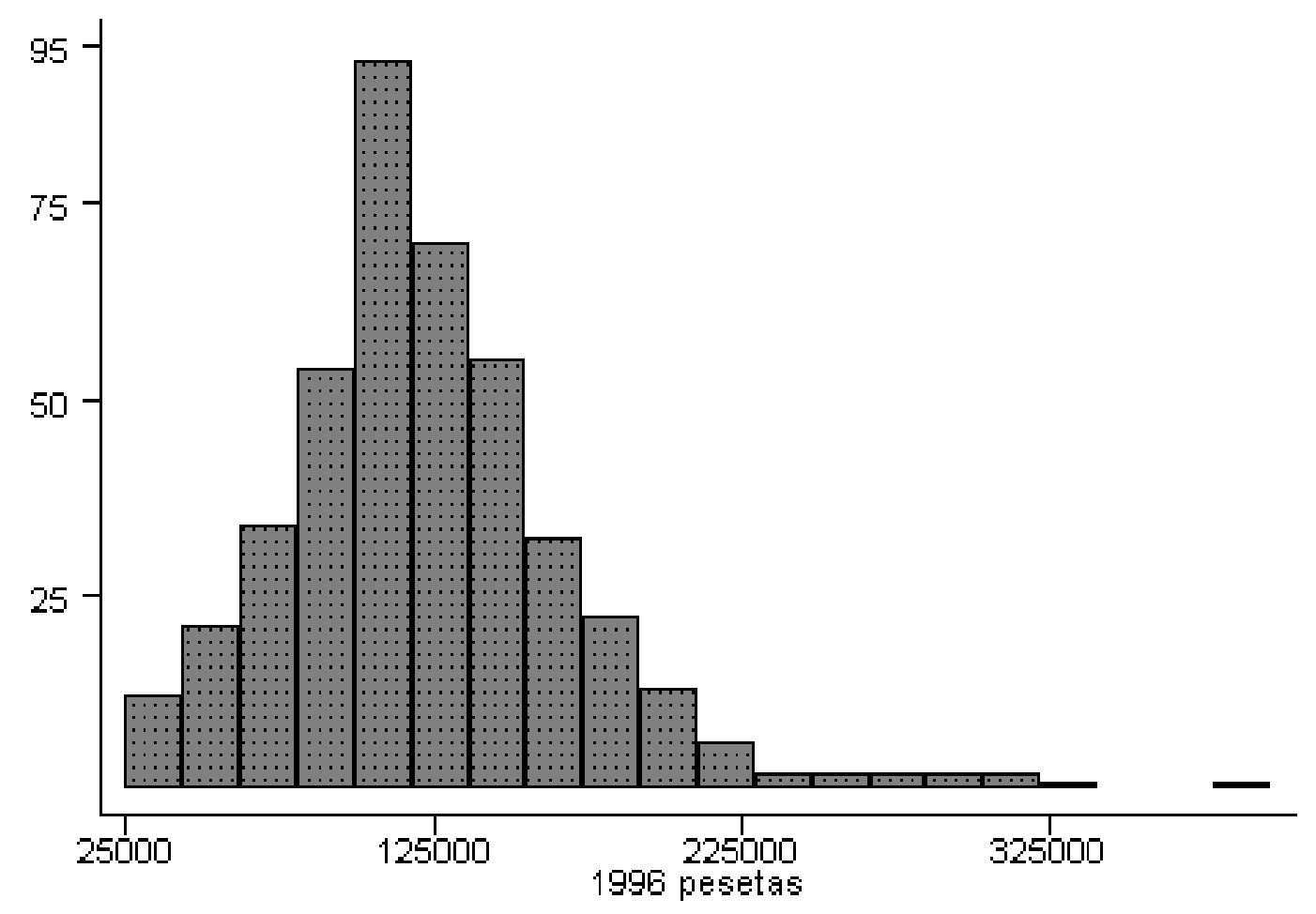


Figure 3: Estimated reservation wages

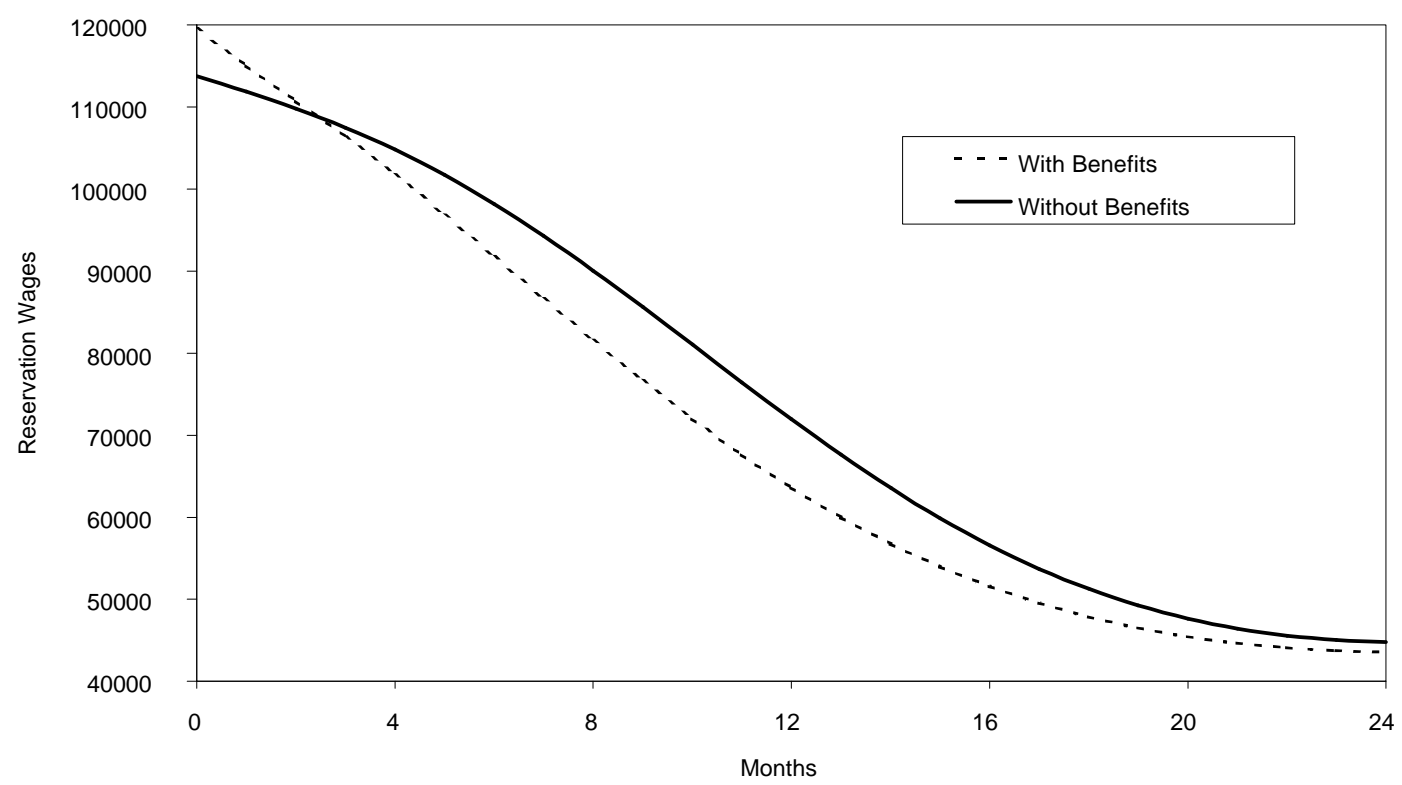


Figure 4: Estimated acceptance probabilities

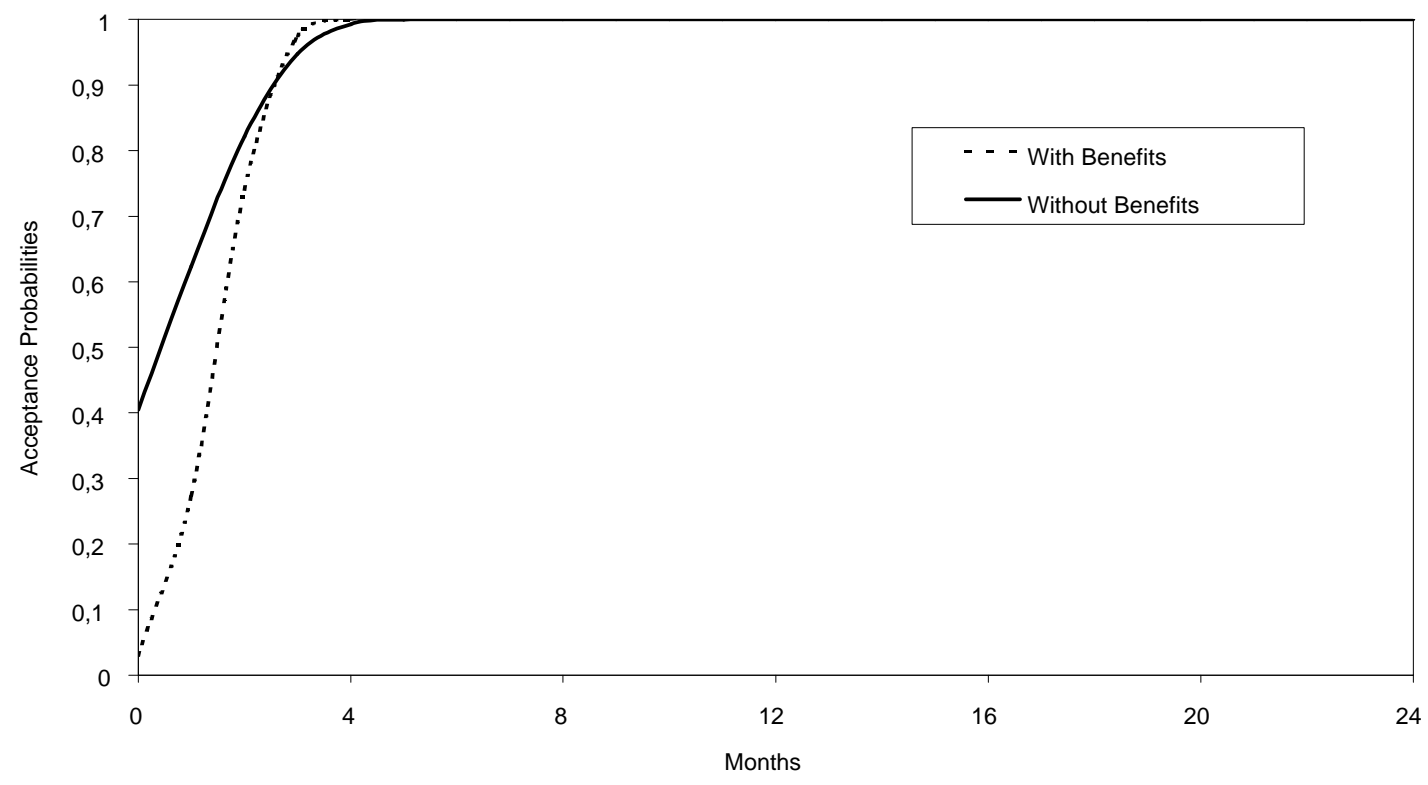


Figure 5: Estimated hazard rates: the effect of unemployment benefits

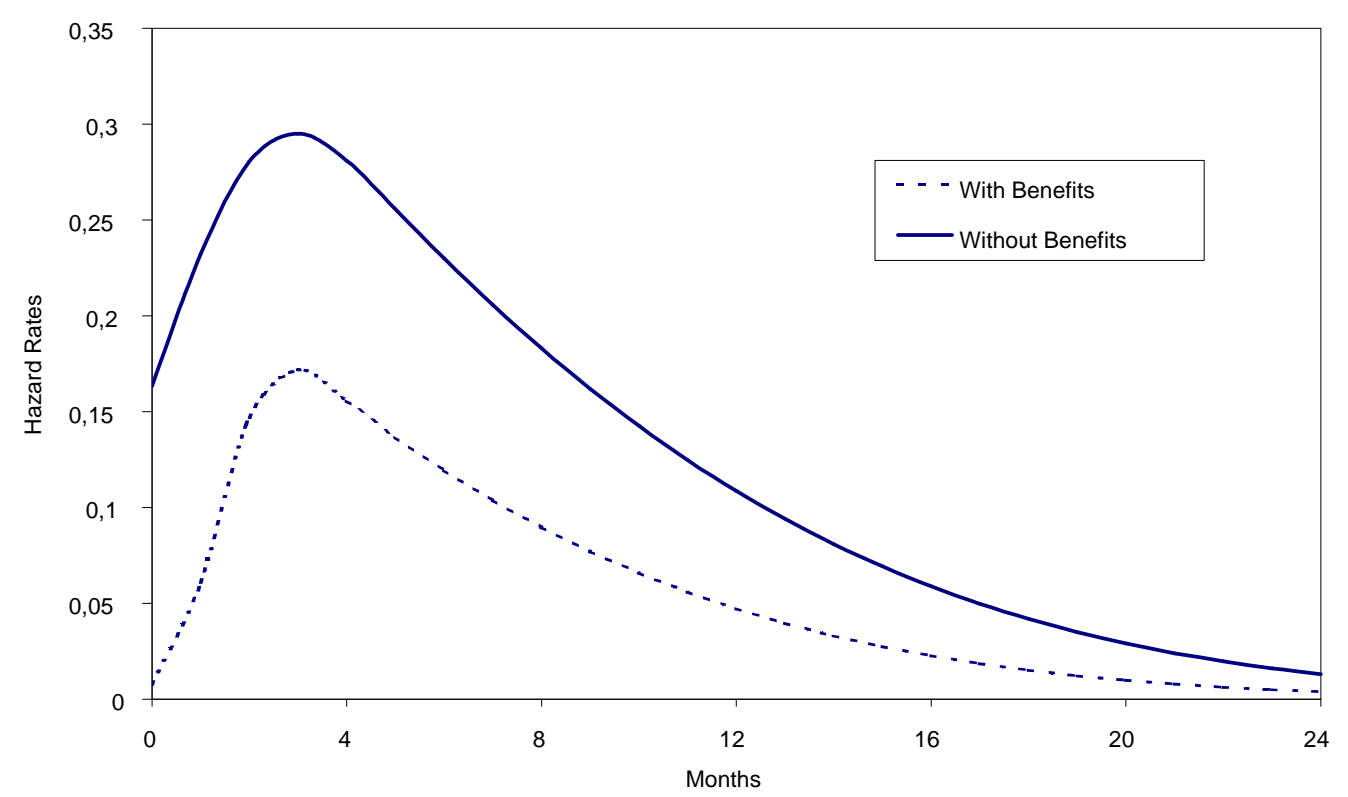


Figure 6: Estimated hazard rates: the effect of skill

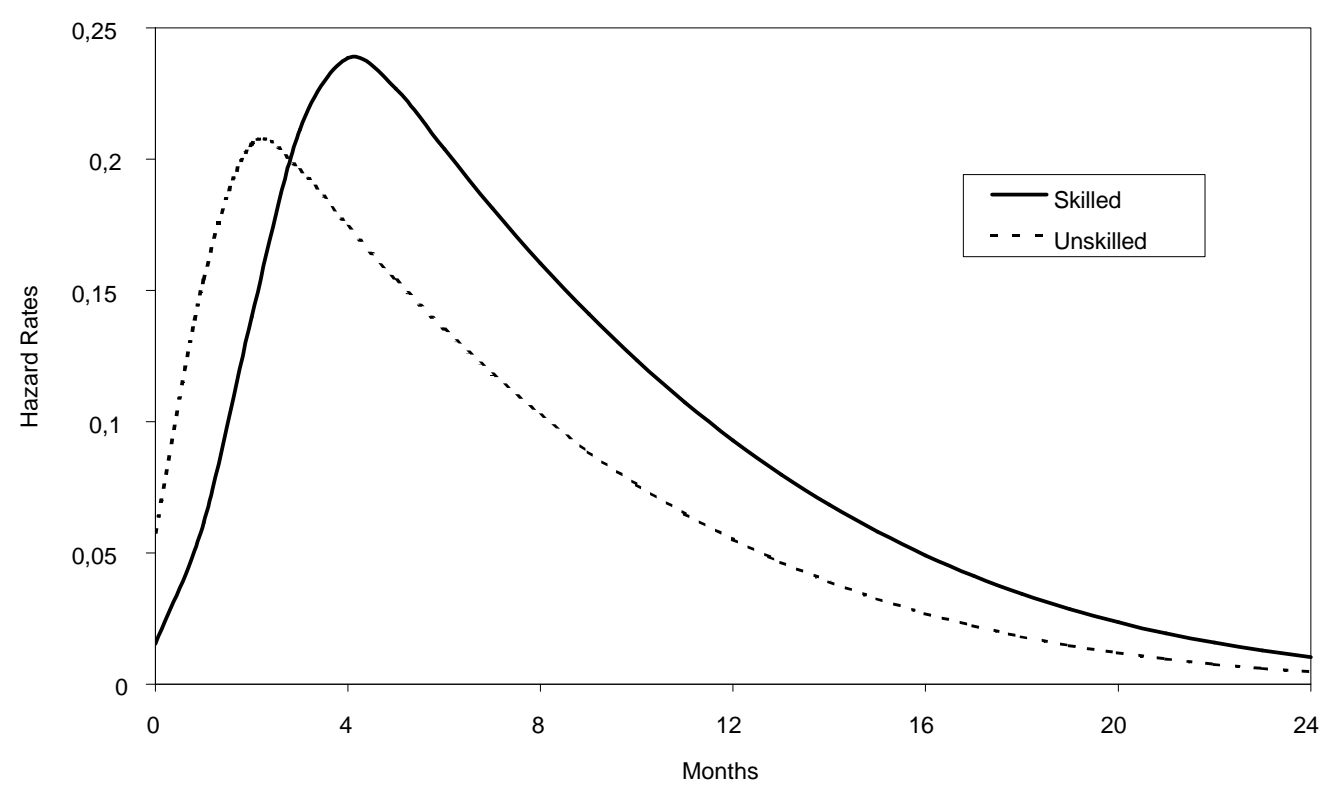

